\title{
Filsafat Pendidikan Islam: Telaah Epistimologi Ilmu
}

\section{Mustafa}

\begin{abstract}
Absrak
Philosophy and education are, them, but two stages of the some endeavor; philosophy to think out better values and idealism, education to realize these in life, in human personality. Philosophizing and education are, ten, but two stages of the some endeavor; The Islamic theory of education is fundamentally based upon the Qur'anic concepts. In this theory the door is left open for concepts which come from different fiels of knowledge propided thet they fit the Qur'anic perspective. All elements which be reconciled witch Islamic principles should be excluded..Philosophizing to think out better values and idealism, education to realize these in life, in human personality. The ultimate aim of muslim education lies in the realization of complete submission to Allah on the level of the individual, the community and humanity at large. In Islamic educational field, howewer, there are some prominent figurest who have highly proposed educational theories in Islam. Baced on this fact, Islamic educational has two sourcesr for their educational process, and therefore, Islamic education must combined in balance they fungtion of school with the rule of society.
\end{abstract}

Kata Kunci: Filsafat-Pendidikan Islam dan Epistimologi ilmu

\section{Pendahuluan}

Filsafat pendidikan Islam keberadaannya masih diperdebatkan dalam wilayah studi Islam. Karena itu, wacana-wacana baru selalu dimunculkan agar bisa merekonstruksi struktur fudamental keilmuannya, baik dari segi ontologi, epistimologi ataupun aksiologi. Redekonstruksi di pandang perlu karena filsafat pendidikan masih mengandung banyak wajah, antara menginduk kepada ilmu fiulsafat, kepada ilmu pendidikan, atau kepada ilmu filsafat pendidikan. Oleh karena itu kajian ini mencoba mengungkap secara epistimologi ilmu.

Di dalam filsafat ilmu, dibahas tiang-tiang penyangga eksistensi sebuah ilmu, yang merupakan cabang-cabang agama filsafat ilmu. Tiang penyangga ilmu terdiri dari tiga aspek, yaitu ontologi, epistimologi dan aksiologi. ${ }^{1}$ aspek ontologis keilmuan biasanya mempermasalahkan apa yang dikaji sebuah ilmu pengetahuan. Aspek epistimologi mencoba menelaah ilmu pengetahuan dari segi sumber dan metode ilmu yang digunakan dalam rangka mencapai suatu kebenaran ilmiah. Aspek aksiologis suatu ilmu pengetahuan mempertanyakan untuk apa suatu ilmu pengetahuan digunakan atau dengan kata lain, aksiologi diartikan sebagai teori nilai yang berkaitan dengan kegunaan suatu ilmu pengetahuan. ${ }^{2}$

\footnotetext{
${ }^{1}$ Noeng Muhadjir, Filsafat Ilmu: Telaah Sistematis Fungsional Komparatif (Cet. I; Jogjakarta: Rakesarasin, 1998), h. 49.

${ }^{2}$ Ibid., h. 234
} 
Pengetahuan ilmiah akan dapat menghasilkan kebenaran ilmiah, yaitu sebuah kebenaran yang diperoleh dengan sarana dan tata cara tertentu yang hasilnya dapat dikaji ulang oleh siapapun dan kapanpun dengan kesimpulan yang sama. ${ }^{3}$ Karena kebenaran ilmiah yang dihasilkan, maka ia disebut a bigher level of knowledge. Pengetahuan ilmiah ini secara terus menerus dikembangkan dan dikaji manusia secara mendalam, sehingga melahirkan apa yang disebut filsafat ilmu (philosophy of science, wissenscatlehre atau wetenschapsleer). Dengan demikian, filsafat ilmu merupakan pengembangan secara mendalam dan filosofis dari apa yang disebut filsafat pengetahuan.

Berdasarkan uraian-uraian pengantar diatas, bab ini akan membahas secara filosofis apa yang akan menjadi landasan keilmuan filsafat pendidikan islam. Untuk itu, yang menjadi fokus permasalahan adalah apa landasan ontologis, epistimologis, dan aksiologis filsafat pendidikan islam?

\section{Filsafat Pendidikan Islam Dalam Timbangan Epistimologi Ilmu}

Filsafat, falsafah atau philosophia secara harfiah berarti cinta kepada kebijaksanaan atau cinta kepada kebenaran. Maksudnya, setiap orang yang berfilsafat akan menjadi bijaksana. Orang yang cinta kepada pengetahuan disebut philosopher, yang dalam bahasa Arab disebut failasuf. Pencinta kepada pengetahuan adalah orang yang menjadikan pengetahuan sebagai tujuan hidupnya. Dengan kata lain, ia mengabdikan diri dan hidupnya kepada pengetahuan. Filsafat secara sederhana berarti "alam pikiran" atau "alam berpikir". Berfilsafat artinya berfikir. Namun tidak semua berfikir berarti berfilsafat. Berfilsafat adalah berpikir secara mendalam (radikal)dan sungguh-sungguh. Ada sebuah semboyan yang mengatakan bahwa "setiap manusia adalah filosof". Semboyan ini benar adanya, sebab semua manusia berpikir akan tetapi, secara filosofis, semboyan itu tidak benar, sebab tidak semua manusia yang berpikir adalah filosof. Filosof hanyalah orang yang memikirkan hakikat segala sesuatu dengan sungguhsungguh dan mendalam. Filsafat adalah hasil akal budi manusia yang mencari dan memikirkan suatu kebenaran dengan sedalam-dalamnya. Dengan kata lain, filsafat adalah ilmu yang mempelajari dengan sungguh-sungguh hakikat kebenaran segala sesuatu.

Dari pengertian ini, ada lima unsur yang mendasari sebuah pemikiran filsafat, yaitu:

a. Filsafat itu sebuah ilmu pengetahuan yang mengandalkan penggunaan akal (rasio) sebagai sumbernya. Akal digunakan sebagai sumber filsafat.

b. Tujuan filsafat adalah mencari kebenaran atau hakekat segala sesuatu yang ada.

c. Objek material filsafat adalah segala sesuatu yang ada. Segala sesuatu yang ada mencakup " ada yang tampak" dan "ada yang tidak tampak" . ada yang tampak adalah dunia empiris, dan ada yang tidak tampak adalah alam metafisika.. Adapun objek formal filsafat adalah sudut pandang yang menyeluruh, radikal dan objektif tentang yang ada, untuk dapat diketahui hakekatnya. ${ }^{4}$

d. Metode yang digunakan dalam berpikir filsafat adalah mendalam, sistematik, radikal dan universal.

\footnotetext{
${ }^{3}$ Sumadi Suryabrata, Metodologi Penelitian (Cet. V; Jakarta : Rajawali Pers, 1989), h. 3-6.

${ }^{4}$ Lasiyo dan Yuwono, Pengantar Ilmu Filsafat (Yogyakarta: Liberty, 1985), h. 6.
} 
e. Oleh karena filsafat itu menggunakan akal sebagai sumbernya, maka kebenaran yang dihasilkannya dapat diukur melalui kelogisannya.

Dengan kelima unsur diatas, tampak bahwa filsafat merupakan sebuah ilmu pengetahuan, karena memenuhi beberapa syarat ilmu pengetahuan, karena memenuhi beberapa syarat ilmu pengetahuan. Oleh karena itu, banyak ahli yang menyebut filsafat sebagai ilmu (science). Dalam kaitan ini, Saifuddin Anshari bahkan menyebut filsafat sebagai "ilmu istimewa", karena filsafat mencoba menjawab persoalan-persoalan yang tidak dapat dijawab oleh ilmu pengetahuan biasa.

\section{Analisis Teoritis Filsafat Pendidikan Islam}

Filsafat pendidikan pada umumnya dinyatakan bahwa filsafat pendidikan dipandang sebagai pembahasan yang sistematis tentang masalah-masalah pendidikan pada tingkat filosofis, yaitu menyelidiki suatu persoalan pendidikan sehingga direduksi kedalam pokok bahasan metafisika, epistimologi, etika, estetika maupun kombinasi dari semuanya itu. ${ }^{5}$

Dalam pembahasan filsafat pendidikan, persoalan-persoalan tersebut dapat disederhanakan ke dalam tiga persoalan pokok, yaitu pandangan mengenai realita yang dipelajari oleh metafisika atau ontologi, pandangan mengenai pengetahuan yang dipelajari oleh epistimologi, dan pandangan mengenai nilai yang dipelajari oleh aksiologi, termasuk didalamnya etika dan estetika. ${ }^{6}$

Dengan demikian dapat difahami bahwa filsafat pendidikan termasuk filsafat terapan atau filsafat praktik pendidikan. Dalam arti luas filsafat pendidikan dapat dibedakan menjadi dua bagian yaitu, 1) Filsafat praktik pendidikan, dan 2) Filsafat ilmu pendidikan. Filsafat praktik pendidikan adalah analisis kritis dan komprehensif tentang bagaimana seharusnya pendidikan diselenggarakan dan dilaksanakan dalam kehidupan manusia. ${ }^{7}$ Jika dikaitkan antara sistem pemikiran filsafat dengan pendidikan menurut Muhaimin, maka dalam lapangan metafisika misalnya, antara lain diperlukan adanya pendirian mengenai pandangan dunia yang bagaimanakah yang diperlukan dalam pelaksanaan. Dalam lapangan epistimologi, antara lain diperlukan penyusunan dasardasar kurikulum. Kurikulum yang biasa dikaitkan dengan sebagai serangkaian kegiatan atau sarana untuk mencapai tujuan pendidikan, diibaratkan sebagai jalan raya yang perlu dilewati oleh peserta didik dalam usaha mengenal dan memahami pengetahuan. Agar para peserta didik berhasil dalam mencapai tujuan itu, maka secara bertahap mereka berusaha mengenal hakekat pengetahuan. Dalam lapangan aksiologi, yakni yang mempelajari nilai-nilai, juga sangat dekat dengan pendidikan, karena dunia nilai (etika dan estetika) juga menjadi dasar pendidikan, yang selalu dipertimbangkan dalam penentuan tujuan pendidikan. Disamping itu pendidikan sebagai fenomena kehidupan sosial, kultural dan keagamaan tidak dapat dilepas dari sistem nilai. Dan dalam lapangan logika, sebagai cabang filsafat yang meletakkan landasan ajaran berfikir yang benar dan valid, sangat diperlukan dalam pendidikan kecerdasan. Pelaksanaan pendidikan menghendaki seseorang mampu mengutarakan pendapat dengan benar dan valid sehingga

${ }^{5}$ Harry S. Broudy, Building A Philosophy of Education (New Jersey: Englewood Cliffs, Prentice Hall, Inc, 1961), h. 14.

${ }^{6}$ Imam Barnadib, Filsafat Pendidikan (Sistem dan Metode) (Yogyakarta: FIP IKIP, 1987), h. 20

${ }^{7}$ Redja Mudyahardjo, Filsafat Ilmu Pendidikan (Bandung : Remaja Rosdakarya, 2001), h. 5 
diperlukan penguasaan logika. ${ }^{8}$ Karena itu hubungan antara filsafat dan pendidikan merupakan keharusan, terutama menjawab persoalan-persoalan pendidikan pokok dan mendasar yang dihadapi oleh pendidikan. Brubacher sebagaimana dikutip oleh Ozmon \& Craver menyarankan agar persoalan-persoalan yang mendasar tentang pendidikan dibahas dan dipecahkan menurut teori filsafat. ${ }^{9}$ Sebagai implikasinya diperlukan bangunan filsafat pendidikan yang kokoh dalam pelaksanaan sistem pendidikan. Jika tidak demikian, dikhawatirkan akan terjadi : (1) pendidikan akan terapung-apung (tanpa tujuan), (2) tujuan-tujuan pendidikan akan samar-samar (meragukan), bertentangan, dan tidak menunjang kesetiaan, (3) ukuran-ukuran dasar pendidikan menjadi sangat longgar, (4) ketidak menentuan peranan pendidikan dalam suatu masyarakat, (5) sekolah-sekolah akan memberikan banyak kebebasan kepada siswa dan tidak mampu memupuk apresiasi terhadap otoritas dan kontrol, dan (6) sekolah akan menjadi sangat sekuler dan mengabaikan agama.

Ibarat sebuah bangunan rumah, maka bangunan filsafat pendidikan Islam itu mencakup berbagai dimensi, yaitu : Pertama, dimensi bahan-bahan dasar yang menentukan kuat atau tidaknya suatu fondasi bangunan. Dalam konteks filsafat pendidikan berarti sumber-sumber atau semangat pemikiran dari para pemikir pendidikan Islam itu sendiri. Kedua, dimensi fondasi bangunan itu sendiri, yang berupa prinsip atau dasar dan asas (kebenaran yang menjadi pokok dasar) berfikir dalam menjawab persoalan-persoalan pokok pendidikan yang termuat dalam sistem (komponen-komponen pokok aktivitas) pendidikan Islam. Ketiga, adalah dimensi tiang-tiang penyangga yang berupa struktur ide-ide dasar serta pemikiran-pemikiran yang fundanmental yang telah dirumuskan oleh pemikir pendidikan Islam itu sendiri dalam mengembangkan, mengarahkan dan memperkokoh bangunan sistem pendidikan Islam. ${ }^{10}$

Sistematika karya (pemikiran) filsafat pendidikan Islam diawali dengan menampilkan: pertama, sumber-sumber pemikiran pendidikan, yaitu al-Qur'an, alSunnah dan sebagai sumber pendukungnya yang termasuk di dalamnya metodologi pengembangannya yang merupakan manivestasi dari semangat pemikirannya; kedua, kajian tentang dimensi-dimensi substansial prinsip atau dasar pemikiran terhadap persoalan-persoalan komponen pokok aktivitas pendidikan Islam, yang mencakup tinjauan filosofis tentang hakikat manusia, alam semesta, masyarakat, ilmu pengetahuan, nilai/akhlak, dan hakikat hidup/kehidupan.

Berbagai tinjauan tersebut dilandasi oleh sumber-sumber pemikiran atau metodologi pengembangannya, sehingga meghasilkan konsep-konsep yang menjadi landasan filosofis dalam mengkaji persoalan hakikat komponen-komponen pokok kativitas pendidikan Islam; dan ketiga, tujuan filosofis tentang komponen-komponen pokok aktivitas pendidikan Islam, baik yang berkaitan dengan hakikat tujuan pendidikan Islam, kurikulum pendidikan Islam, pendidik dalam pendidikan Islam, peserta didik dalam pendidika Islam, hakikat metode dalam pendidikan Islam, dan hakikat lingkungan dalam pendidikan Islam. Rumusan-rumusan konseptual tentang masalah tersebut akan berkembang menjadi teori-teori pendidikan Islam setelah adanya pembuktian secara logis dan empiris.

\footnotetext{
${ }^{8}$ Muhaimin, Wacana Pengembangan Pendidikan Islam (Surabaya: Pusat Studi Agama, Politik dan Masyarakat, 2003), h. 31.

${ }^{9}$ Ibid.

${ }^{10}$ Muhaimin, Ibid., h. 32.
} 
Pemikiran (filsafat) pendidikan Islam tidak bisa juga dilepaskan dari alur pemikiran yang dikembangkan oleh para pemikirnya. Selama ini pemikiran filsafat pendidikan pada umumnya dikategorikan ke dalam dua kelompok (aliran), yaitu : pertama, aliran filsafat kritis dalam pendidikan atau masa pemikiran yang bersifat maju atau progresif dalam pemikiran, dan yang kedua, aliran atau mazhab pemikiran filsafat pendidikan yang bersifat tradisional. ${ }^{11}$ Ukuran maju atau progresif dan tradisional biasanyadilihat dari sejauh mana peranan pendidikan dan anak didik keseluruhan upaya pendidikan. Konsep pendidikan bersifat tradisional bila menekankan peranan pendidik dan hal-hal di luar anak didik. Dalam alam pendidikan tradisional anak didik seolah-olah dijadikan obyek pasif yang perlu disesuaikan terhadap hal-hal yang berada di luar dirinya. Sebaliknya suatu konsep pendidikan bersifat maju atau progresif apabila ia menempatkan anak didik itu sendiri. Kedua konsep tersebut terus mempertahankan diri dan berkembang dengan keunggulan dan kelemahan masing-masing.

Pemikiran pendidikan Islam juga dikelompokkan ke dalam dua alur pemikiran dalam menjawab persoalan pendidikan, sebagaimana temuan penelitian Abdullah (1982), yaitu : pertama, kelompok yang berusaha mengangkat konsep pendidikan Islam dari alQur'an dan al-Hadits saja, sehingga konsep filsafatnya hanya berasal dari kedua sumber ajaran Islam tersebut ; dan kedua, kelompok yang menghendaki adanya keterbukaan terhadap pandangan hidup non Islami dan berusaha meminjam serta memasukkan konsep pemikirannya ke dalam filsafat pendidikan Islam. ${ }^{12}$

Bertolak dari pandangan diatas, teori postmodern menjadi salah satu landasan filosofis dalam pengembangan ilmu pendidikan Islam, dengan melakukan modifikasi konsep yang tidak begitu saja mengadopsi pemikiran postmodernis, justru ia melakukan kontekstualisasi dengan ajaran Islam. Oleh karena itu perkembangan pemikiran dalam pendidikan dapat dipetakan sehingga menjadi tipologi-tipologi pemikiran. Di Amerika Serikat berkembang aliran-aliran pemikiran (filsafat) pendidikan, yang dapat dipetakan kedalam dua kelompok, yaitu tardisional dan kontemporer. Sedangkan yang termasuk dalam kelompok kontemporer adalah progresivism, Rekonstructionism, dan Existentialism.

Dalam lapangan pendidikan, masing-masing aliran tersebut terwujud dalam kemungkinan-kemungkinan sikap dan pendirian para pendidik, seperti (1) sikap konservatif, yakni mempertahankan nilai-nilai budaya manusia, sebagai perwujudan dari essensialism; (2) Sikap regresif, yakni kembali kepada jiwa manusia yang menguasai abad pertengahan, yaitu agama, sebagai perwujudan dari perenialism; (3) sikap bebas dan modifikatif sebagai perwujudan dari progresivism; (4) sikap radikal rekonstruktif sebagai perwujudanReconstrucionism; dan (5) sikap yang menekankan keterlibatan peserta didik dala kehidupan empiris utuk mencari pilihan dan menemukan jati dirinya, atau menurut Brubacher (1982): "...in the end the learner's identity is fiund in his commitments. What he chooses, that he becomes adalah perwujudan dari exsistentialism.

Oleh karena itu wilayah kajian pemikiran (filsafat) pendidikan dapat lihat dari berbagai dimensi, Buchari melihat dua dimensi, yaitu dimensi lingkungan pendidikan,

\footnotetext{
${ }^{11}$ Ibid, h. 4.

12 Abdurrahman Saleh Abdullah, Education Theory A Quranic Out-look, (Makalah alMukarramah: Umm al-Qura University, 1982), h. 35-36.
} 
dan dimensi jenis permasalahan pendidikan. ${ }^{13}$ Dan dapat ditambahkan dengan dimensi waktu, dan dimensi ruang geografis. ${ }^{14}$

Muhaimin mencoba lebih mengembangkan kearah yang lebih metodologis dan praktis, yang berangkat dari teori dan pemetaan pemikiran dan juga menilai secara histories-sosiologis pendidikan dengan di direduksi kepada pengembangan yang lebih praktis sesuai dengan pengembangan disekolah. Maka dalam penelitian akan dicoba yang dimulai dari teori kemudian bagaimana mengimplementasikannya dalam pengembangan pendidikan Islam kedepan.

\section{Penutup}

Dalam filsafat ilmu filsafat Islam dapat dikaji dalam tiga aspek, yaitu aspek ontologis keilmuan biasanya mempermasalahkan apa yang dikaji sebuah ilmu pengetahuan. Aspek epistimologi mencoba menelaah ilmu pengetahuan dari segi sumber dan metode ilmu yang digunakan dalam rangka mencapai suatu kebenaran ilmiah. Aspek aksiologis suatu ilmu pengetahuan mempertanyakan untuk apa suatu ilmu pengetahuan digunakan atau dengan kata lain, aksiologi diartikan sebagai teori nilai yang berkaitan dengan kegunaan suatu ilmu pengetahuan.

Filsafat pendidikan Islam adalah konsep berfikir tentang kependidikan yang bersumber atau berlandaskan pada ajaran Islam tentang kemampuan manusia untuk dapat dibina dan dikembangkan serta dibimbing menjadi manusia muslim yang seluruh pribadinya dijiwai oleh ajaran Islam. Kajian filosofis yang digunakan filsafat pendidikan Islam mengandung arti bahwa filsafat pendidikan Islam itu merupakan pemikiran yang mendalam, sistematik, radikal, dan universal dalam rangka mencari kebenaran, inti hakikat pendidikan Islam.

Filsafat pendidikan Islam berdasarkan wahyu, tidak semata berpijak humanistik, tidak mengenal kebenaran terbatas, tapi universal. Berusaha mengembangkan pandangan yang integral dan mengintergralkan pandangan antara dunia dan akhirat sekaligus. Filsafat pendidikan Islam mengembangkan semua aspek kepribadian, mulai akal, intuisi, akal budi dan inderawi. Ide-ide filsafat pendidikan Islam selain bersifat teoritik juga realistik yang dapat diwujudkan dalam tingkah laku, dan mudah transformasikan dalam kehidupan.

13 Muhaimin, op. cit, h. 15.

14 Soedomo, M., Aktualisasi Pengembangan Ilmu Pendidikan Islam Dalam Pembangunan Nasional (Malang : IKIP, 1990), h. 21. 
Jurnal Iqra’ Vol.3. No.1, Januari-Juni 2009

\section{Daftar Pustaka}

Abdullah, Abdurrahman Saleh Education Theory A Quranic Out-look, Makah alMukarramah: Umm al-Qura University, 1982.

Ahmad Jamal, Muhammad, Nahwa Tarbiyyah Islamiyyah, Cet. I; Jeddah: Tihamah, 1980.

Al-Sayyid Sulthan, Muhammad, Mafahim Tarbawiyyah fi al-Islam, Cet. II; Kairo:Dar al-Ma'arif, 1981.

IKIP, 1987.

Barnadib, Imam Filsafat Pendidikan (Sistem dan Metode,,) Yogyakarta: FIP

Mudyahardjo, Redja Filsafat Ilmu Pendidikan, Bandung : Remaja Rosdakarya, 2001.

Muhaimin, Pengembangan Kurikulum Pendidikan Agama Islam di Sekolah, Madrasah, dan Perguruan Tinggi, Jakarta : PT. Raja Grapindo, 2005.

Muhaimin, Wacana Pengembangan Pendidikan Islam, Surabaya : Pusat Studi Agama, Politik dan Masyarakat, 2003.

Muhadjir, Noeng filsafat ilmu: telaah sistematis fungsional komparatif, cet. I., Jogjakarta : Rakesarasin, 1998.

Suryabrata, Sumadi, Metodologi Penelitian, Cet. V; Jakarta : Rajawali Pers, 1989.

Lasiyo dan Yuwono, Pengantar Ilmu Filsafat Yogyakarta: Liberty, 1985.

S. Broudy, Harry Building a Philosophy of Education, New Jersey: Englewood Cliffs, Prentice Hall, Inc, 1961.

Soedomo, M., Aktualisasi Pengembangan Ilmu Pendidikan Islam Dalam Pembangunan Nasional, Malang : IKIP, 1990. 